\title{
Correction to: Identification of novel human RANK isoforms generated through alternative splicing. Implications in breast cancer cell survival and migration
}

Anastasios D. Papanastasiou ${ }^{*}{ }^{\dagger}$, Chaido Sirinian ${ }^{\dagger}$ and Haralabos P. Kalofonos

\section{Correction}

After the publication of this article [1] we noticed that in Fig. 1, the gel images (1A and 1B lower panel) were incorrect. The corrected Fig. 1 is presented below. The correction does not affect in any way our results and conclusions.

Received: 14 May 2018 Accepted: 14 May 2018

Published online: 07 June 2018

\section{Reference}

1. Papanastasiou AD, Sirinian C, Kalofonos HP. Identification of novel human

receptor activator of nuclear factor-kB isoforms generated through

alternative splicing: implications in breast cancer cell survival and migration. Breast Cancer Res. 2012;14(4):R112.

*Correspondence: apapanasta@gmail.com

${ }^{\dagger}$ Anastasios D. Papanastasiou and Chaido Sirinian contributed equally to this work.

Clinical and Molecular Oncology Laboratory, Division of Oncology,

Department of Medicine, University of Patras, 26504 Rion, Greece 


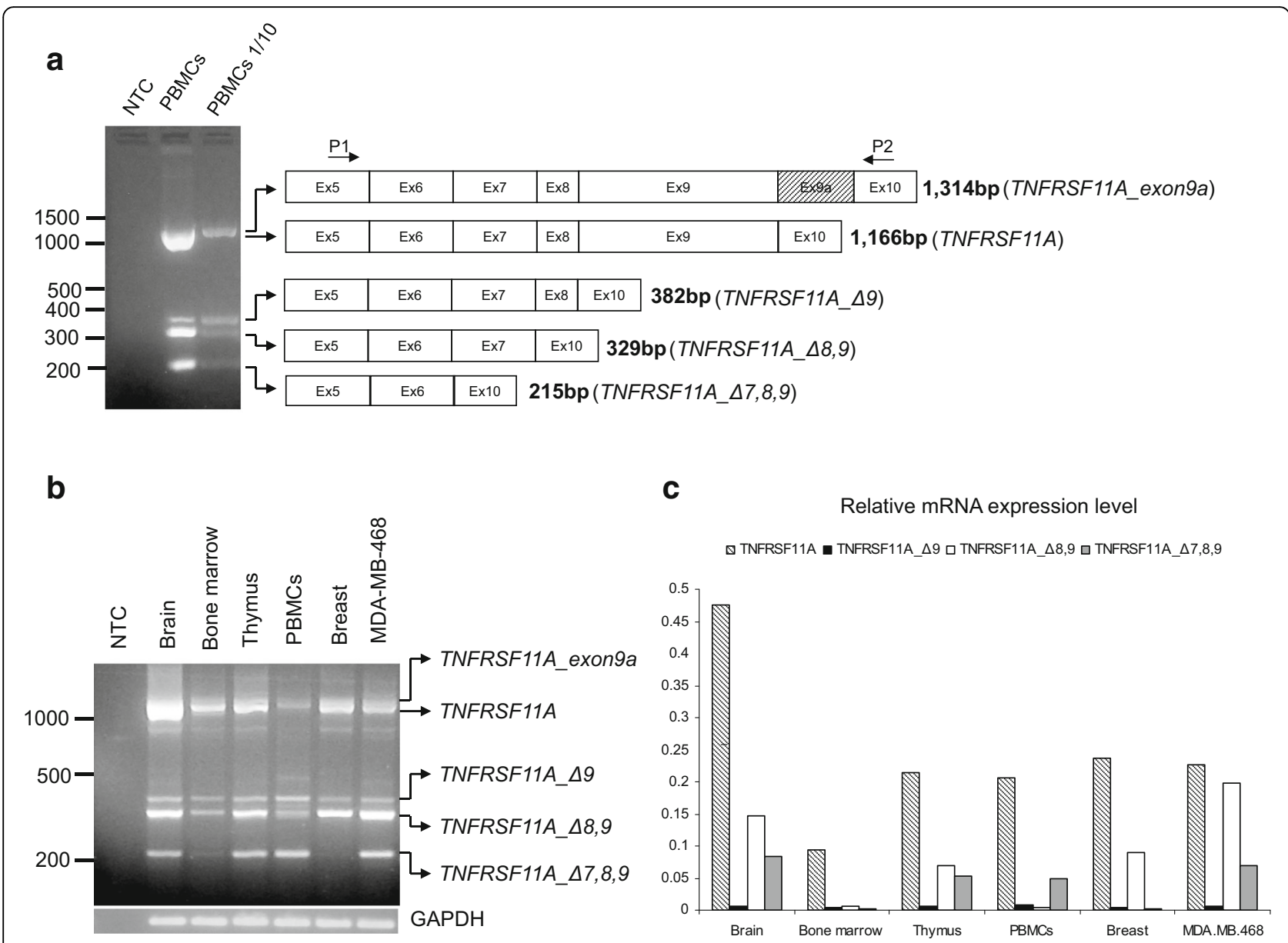

Fig. 1 a. Agarose gel electrophoresis of the PCR products using primers P1 and P2 on CDNA from human PBMCs and the graphical representation of the splice products identified. $\mathbf{b}$. Agarose gel electrophoresis of PCR products depicting TNFRSF11A variant distribution from a panel of human normal tissue RNAs and MDA-MB-468 as a control. c. Quantitative RT-PCR of the novel splice variants and wild type RANK from a panel of human normal tissue RNAs. Data normalization was carried out against GAPDH housekeeping gene 